\title{
AREVA Control Room Accident Filtration System CRAFT
}

Jens Beck, Axel Hill and Marina Welker

AREVA GmbH, 91058 Erlangen, Germany

Received: July 12, 2016 / Accepted: July 27, 2016 / Published: November 30, 2016.

\begin{abstract}
The AREVA CRAFT (control room accident filtration system) is a solution that maintains the proper air conditions in the main control room and emergency control facilities by filtering the air and removing noble gases in case of a severe accident in a nuclear power plant with increased activity concentration in the plant environment.
\end{abstract}

Key words: CRAFT, severe accident mitigation, control room protection.

\section{Introduction}

Severe accident scenarios bear a high risk of contaminating the vicinity by the release of airborne radioactive substances to the environment [1-4]. Unexpected leakages in the containment due to leaking containment isolation valves or HVAC (heating, ventilation and air-conditioning) dampers may cause such releases. While particulates, such as aerosols, can be effectively retained in commonly applied filtering systems, the retention of gaseous fission products, such as krypton- 85 or xenon-133, is difficult. The release of noble gases leads to a significant dose exposure of the emergency response team and impairs the execution of severe accident countermeasures. Activity release originating from $\mathrm{Kr}-85$ ( $\mathrm{t} 1 / 2=10.8$ a) fades by three orders of magnitude after approximately $11 \mathrm{~h}$ already. The activity released by Xe-133 (t1/2= $5.3 \mathrm{~d})$ emissions however remains on a high level for more than a month after a severe accident (Fig. 1 according to Ref. [8]).

The response to an emergency is generally coordinated from the main control room or from

Corresponding author: Dr.-Ing. Jens Beck, section manager for Waste and Isoptopes at the AREVA GmbH Erlangen. emergency response centers. There are restrictive design requirements for such rooms to withstand major natural events: provision of sufficient space for personnel, sufficient emergency power sources, prevention of the inflow of radioactive substances, etc. During an emergency such facilities must be protected to maintain habitable conditions with respect to high radiation levels, presence of smoke, fire, toxic gases, etc.

The OECD (Organisation for Economic Co-operation and Development) has provided recommendations [2] to take measures to prevent activity (including noble gases activity) from entering inhabited rooms and areas in order to reduce exposure and protect the emergency response team. The highest possible activity impact on the personnel should not exceed $100 \mathrm{mSv} / 7$ days in case of a severe accident. This approach is followed by the Japanese NRA (Nuclear Regulation Authority) which requires doses to personnel in control rooms in case of a severe accident to be kept below $100 \mathrm{mSv} / 7$ days [5].

The main objective is to ensure safe working conditions for as long as possible. Although seven days of safe working conditions are recommended, ideally there should be no time restrictions on severe accident mitigation. 
Based on these requirements and recommendations, AREVA has developed a technical solution to solve this issue.

\section{Areva's Craft}

The CRAFT (control room post-accident filtration) system is designed for post-accident conditions with increased activity concentration in the plant environment during events such as complex accident scenarios in combination with containment leakages. The system is usually on standby and planned to be put into operation during an accident to maintain the habitability of the operator room.
Outside air with fission products enters the CRAFT system via HVAC ducts or via a separate dedicated suction line. Airborne activity is filtered and noble gases are retained so that clean air is supplied to the control room. Exhaust air from the control room is released to the environment via CRAFT (see Fig. 2). CRAFT consists of two main units: an airborne activity unit and a noble gas retention unit. Since the 1970s, many nuclear power plants worldwide have installed an airborne activity filtration system for control rooms. Airborne activity filtration is based on conventional and proven technology. AREVA has installed more than 90 such units worldwide.

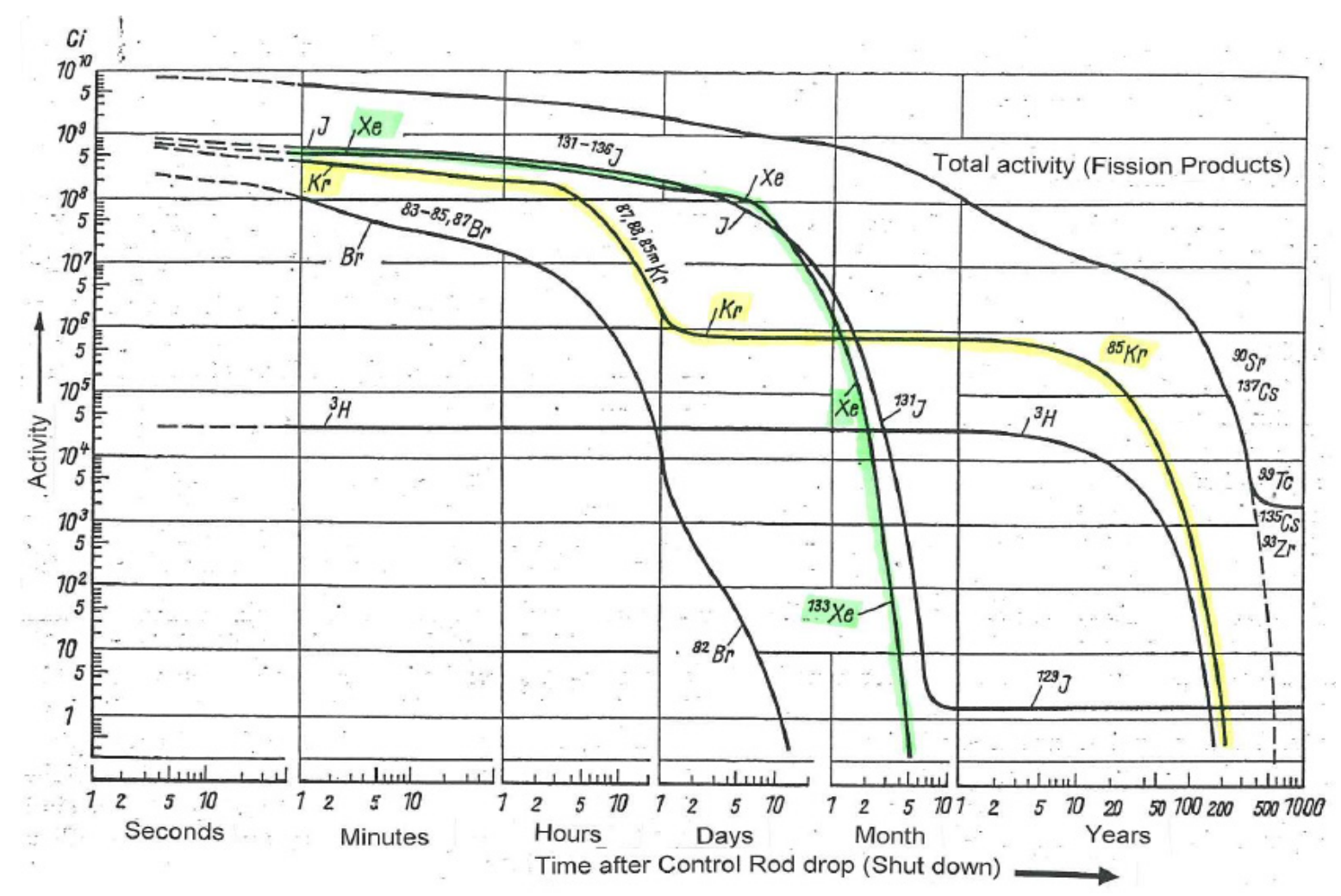

Fig. 1 Activity release of $\mathrm{Kr}-85$ and $\mathrm{Xe}-133$.

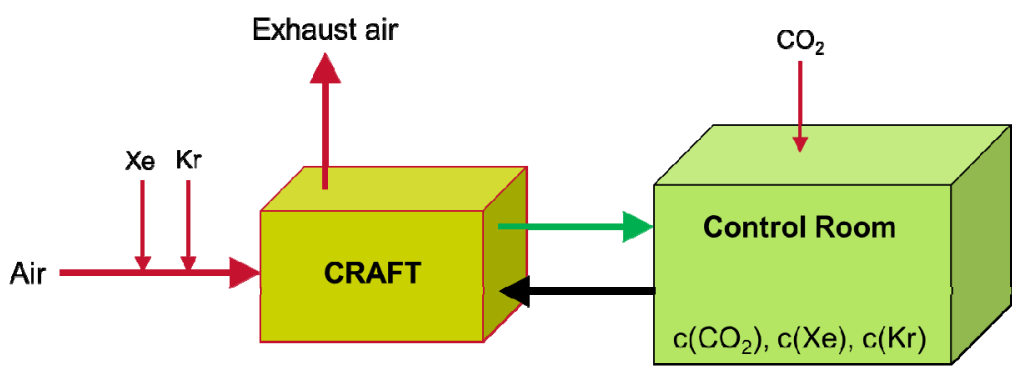

Fig. 2 Operating principle of CRAFT. 


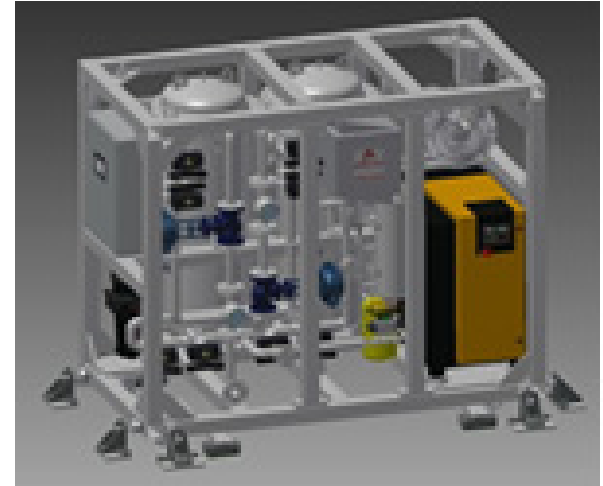

(a)

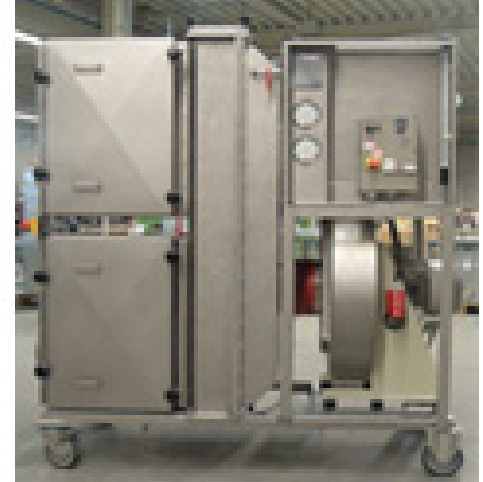

(b)

Fig. 3 (a) Noble gas delay unit size $S$ for 10-15 people; (b) The associated airborne activity unit.

Based on the current evolution in Japanese regulatory requirements to keep the doses to the emergency response team below $100 \mathrm{mSv} / 7$ days [5] in case of a severe accident, AREVA developed a noble gas retention unit to be used either in combination with the existing airborne activity filtration or as a standalone unit. This noble gas retention unit enables an uninterrupted supply of the control room with fresh outside air.

CRAFT has to maintain a habitable control room environment, including the following tasks:

- Air filtration to ensure control room activities;

- Keep the carbon dioxide $\left(\mathrm{CO}_{2}\right)$ concentration at an acceptable limit;

- Keep oxygen $\left(\mathrm{O}_{2}\right)$ concentration at an acceptable limit;

- Filtration of airborne activity (iodine, aerosols);

- Prevention of active noble gas entrance.

\subsection{Airborne Activity Unit}

The airborne activity unit of CRAFT consists of two main stages:

- HEPA (high-efficiency particulate arrestance) filter for aerosol retention;

- Iodine trap filled with activated carbon.

The airborne activity unit of CRAFT is not necessary if the plant has already a similar activity filtration system.

\subsection{Noble Gas Retention Unit}

This application is based on the dynamic adsorption of noble gases in a specially developed activated carbon bed. The noble gas retention unit consists of two trains with such delay beds. The retention effect is based on the fact that the velocity of gas components inside the activated carbon depends strongly on their individual mass. The noble gases xenon and krypton are delayed since they are heavier than the other constituents of air. Due to this absorption effect fresh air reaches the control room before active noble gases break through the delay bed. Shortly before noble gases break through, the flow is switched over to a second delay bed, while the loaded bed is desorbed.

Since 1968, AREVA has performed intensive research into the behavior of activated carbon in delaying radioactive noble gases. The results have been applied to the CRAFT noble gas retention unit.

Moreover, extensive testing programs were carried out by AREVA in order to verify the retention efficiency for noble gases to allow for a significant dose reduction $(<<100 \mathrm{mSv}$ in 7 days). A decontamination factor for krypton of $>3000$ was established and for xenon a decontamination factor of $>$ 1000 while $\mathrm{CO}_{2}$ and $\mathrm{O}_{2}$ concentrations in the air of the supplied rooms were kept to fulfill the dose rate requirements of $100 \mathrm{mSv} / 7$ days [5].

\subsection{Gas Composition Control}

Since CRAFT isolates rooms which are equipped with this filtration system from the ambient air, precautions to limit carbon dioxide concentration are 
essential. Carbon dioxide is exhaled by personnel and must be transported to the outside. The US NRC's (National Research Council's) recommendation is 2.5 vol.\% in the short term (24 hours, emergency exposure guidance level) and 0.8 vol.\% in the long term (up to 90 days, continuous exposure guidance level) [6]. In general, the long-term carbon dioxide concentration in control rooms is to be kept below 0.5-1.5 vol.\% depending on customer requirements.

As carbon dioxide has its own velocity in the delay bed, its concentration in the control room could be exceeded. CRAFT maintains the concentration of carbon dioxide in the control room and is kept below the prescribed limits in long-term operation. At the same time, the oxygen concentration in the concerned room will be kept above $19 \%$.

\section{CRAFT Installation Aspects}

The CRAFT design is flexible and can be adjusted to site-specific requirements:

- Mobile solution or permanently installed;
- Installation inside or outside the building;

- Required air flow.

The air filtration capacity of the CRAFT system can be adjusted to the room size and the number or people in the room, as shown in Table 1. CRAFT requires limited installation space. It causes low installation and maintenance costs during normal operation which helps to reduce running expenditures for a system that is intended to be put into operation only in case of a severe accident.

\section{Mission Time}

The applied technology allows the availability of CRAFT during severe accidents without time limitations. Thus, the control room is protected from too high activity entering via air supply channels (airborne activity and noble gases activity) while a sufficient supply of fresh air is maintained for the time necessary to control the power plant and to perform all mitigation actions required during severe accidents.

Table 1 Different modular unit sizes of CRAFT.

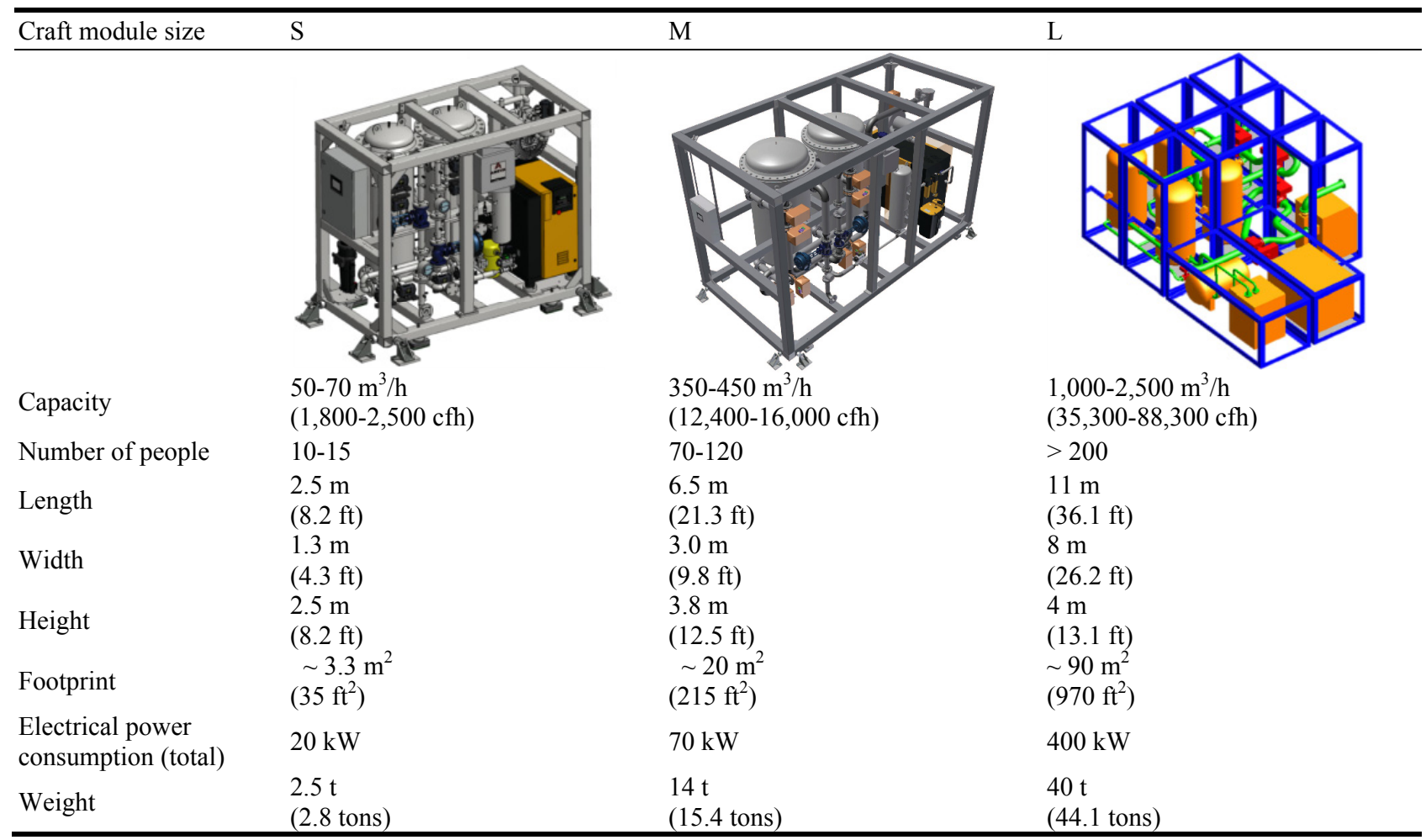




\section{Conclusions}

To maintain suitable air conditions in the main control room and the emergency response center of nuclear power plants in case of a severe accident, AREVA developed the CRAFT system which enables filtering of airborne activity and the retention of noble gases such as Krypton and Xenon. CRAFT has no limitation of operation time. It is designed to operate during the complete accident progression and is suitable even in case of multiple venting scenarios. Moreover, CRAFT covers scenarios at nuclear power plant sites with more than one unit. CRAFT can be used for all types of rooms which need protection, independent from the type of nuclear power plant. The number of people inside the room is the main factor crucial for the dimensioning. The system can be installed inside or outside existing buildings. It can also be provided as a mobile solution within an FLEX concept (diverse and flexible coping strategies [7]) and keeps maintenance costs low.

\section{References}

[1] IAEA: The Use of the International Nuclear and
Radiological Event Scale (INES) for Event Communication, Vienna, August 2014.

[2] OECD/NEA/CSNI Status Report on Filtered Containment Venting, NEA/CSNI/R(2014)7, 02-Jul-2014. Accessed April 28, 2016. https://www.oecd-nea. org/nsd/docs/2014/csni-r2014-7.pdf.

[3] The European PASSAM Project on severe accident source term mitigation. Accessed April 28, 2016. https://gforge.irsn.fr/gf/project/passam/.

[4] Accident Management Insights after the Fukushima Daiichi NPP Accident. Report of the CNRA Task Group on Accident Management, NEA/CNRA/R(2014)2.

[5] National Regulation Authority. 2013. "Outline of New Regulatory Requirements for Light Water Nuclear Power Plants (Severe Accident Measures)." Accessed April 28, 2016. http://www.nsr.go.jp/data/000067119.pdf.

[6] NRC (National Research Council). 1996. Spacecraft Maximum Allowable Concentrations for Selected Airborne Contaminants. Vol. 2. Washington, DC: National Academy Press, 105-89.

[7] Nuclear Energy Institute. 2012. Diverse and Flexible Coping Strategies (FLEX) Implementation Guide. NEI 12-06, Washington.

[8] Feuerbach, R. 2013. Containment Systems Gas Treatment. AREVA, Offenbach. 